УДК $903.02(571.63)$

https://doi.org/10.24852/2587-6112.2021.4.68.79

\title{
МОРФОЛОГИЧЕСКИЙ АНАЛИЗ КЕРАМИКИ НИКОЛАЕВСКОЙ (СМОЛЬНИНСКОЙ) КУЛЬТУРЫ ${ }^{1}$
}

\section{(C) 2021 г. А.А. Боруруева}

В работе анализируются формы и мофологические детали керамики николаевской (смольнинской) культуры Приморья X-XII вв. на основе опубликованных и неопубликованных источников. Рассматривается история исследования культуры и даётся краткая характеристика памятников. Анализируется керамический материал, полученный в разное время в долинах рек Партизанской, Сергеевки, Арсеньевки, Уссури. В результате исследования были выявлены типичные формы керамики рассматриваемой культуры, выделены горшки, корчаги, пароварки, которые являются наиболее часто встречающейся формой, а также миски и чаш, банки, вазы, крышки, которые определялись и систематизировались по археологически целым и частично сохранившимся сосудам. Выделенные сосуды находят свои аналогии в керамике средневековых культур Приморья: бохайской (698-926 гг.), покровской (IX-XIII вв. н.э.), культуры населения Цзинь (1115-1234 гг.) и Восточное Ся (1215-1246 гг), а также в культурах Корейского полуострова: в государстве Пэкче в периоды хансон (18 г. до н.э.475 г. н. э) и саби (538-660 гг.). Определены морфологические особенности керамики николаевской (смольнинской) культуры, являющиеся, помимо сохранения следов выбивки в качестве технического орнамента, культурными признаками, характерными для данной керамической традиции. Донья, закруглённые на стыке дна и тулова, и формы ручек сосудов могут также выступать в качестве культурных маркеров.

Ключевые слова: археология, керамика, средневековье, Приморский край, николаевская культура, смольнинская культура.

\section{MORPHOLOGICAL ANALYSIS OF CERAMICS OF NIKOLAEVSKAYA (SMOLNINSKAYA) CULTURE ${ }^{2}$}

\section{A. A. Borurueva}

The paper analyzes the forms and morphological details of the ceramics of Nikolaevskaya (Smolninskaya) culture of Primorye of the $10^{\text {th }}-12^{\text {th }}$ centuries on the basis of published and unpublished sources. The author examines the history of scientific studies of the culture and provides a brief description of the sites. Material obtained at different time periods in the valleys of the Partizanskaya, Sergeevka, Arsenyevka and Ussuri rivers is analyzed. As a result of the study, the typical forms of ceramics of the culture in question were identified. These are pots, earthenware pots, steamer pots, which are the most common form, dishes and bowls, jars, vases and lids, which were identified and systematized on the basis of archaeologically intact and partially preserved vessels. The selected vessels have counterparts in the ceramics of the medieval cultures of Primorye: Bohai (698-926), Pokrovskaya $\left(9^{\text {th }}-13^{\text {th }}\right.$ centuries AD), culture of Jin (1115-1234) and Eastern Xia (1213-1246) as well as in the cultures of the Korean Peninsula: in the state of Baekje during the periods of Hanseong (18 BC-475 AD) and Sabi (538-660). The morphological features of the ceramics of Nikolaevskaya (Smolninskaya) culture are determined, which, in addition to preserving the traces of pitting as a technical ornament, are cultural features characteristic of this ceramic tradition. Fragments of the bottom, which are rounded at the junction of the bottom and body, and the shape of vessel handles can also act as cultural markers.

Keywords: archaeology, ceramics, the Middle Ages, Primorye, Nikolaevskaya culture, Smolninskaya culture.

\section{Введение}

В изучении истории населения Приморья в период после гибели государства Бохай (698-926 гг.), несмотря на ряд важных открытий, остается еще множество белых пятен. За последние десятилетия научная база пополнилась существенными источниками, освещающими исторические процессы, происходившие в регионе в X-XI вв. Значительная их часть представлена керамическими мате-

\footnotetext{
Работа выполнена при финансовой поддержке гранта РНФ № 20-18-00081 «Археология Дальнего Востока России» (рук. член-корр. РАН Н.Н. Крадин).

2 This work was carried out with the financial support of the Russian Science Foundation grant No. 20-18-00081 "Archaeology of the Russian Far East" (headed by N. N. Kradin, Corresponding Member of the RAS).
} 
риалами. В данной статье анализируются морфологические особенности керамики, относящейся к николаевской (смольнинской) культуре, которая занимала обширную часть территории Приморья в постбохайское время.

Автор использует двойное название одной культуры, так как термины появились независимо друг от друга в 2006 году в работах Е.И. Гельман, В.Э. Шавкунова и И.С. Жущиховской (Гельман, 2006; Жущиховская, Шавкунов, 2006). Тем не менее упоминания о специфичной для средневекового Приморья керамики появляются гораздо раньше. Одним из основных культурных признаков, дающих основание выделять николаевскую (смольнинскую) культуру, стала керамика с «вафельной» выбивкой, т. е. керамика, сохранившая следы выбивки деревянной нарезной колотушкой, вследствие чего образовались ячеистые отпечатки преимущественно прямоугольной и квадратной формы. Население предшествующей и последующих средневековых культур исследуемого региона следы выбивки в подавляющем большинстве случаев тщательно заглаживали или использовали колотушки с гладкой поверхностью. Впервые на присутствие в материалах некоторых памятников Приморья керамики с «вафельным» орнаментом (по терминологии исследователя, «керамики с шахматно-шашечным орнаментом») обратил внимание Э.В. Шавкунов, производя в 1955-1956 г. в крае масштабные разведывательные работы (Шавкунов, 1956). Характерная керамика была обнаружена исследователем на Николаевском городище в 1962 г. (Шавкунов, 1962), а позднее в нижнем слое Чугуевского городища. В 1963 г. был обнаружен и собран материал вокруг небольшого городища Шайга-Редут (Шавкунов, 1963).

Впервые керамика с «вафельной» выбивкой как материал, который позволит детализировать периодизацию средневековых культур Приморья, была рассмотрена Е.И. Гельман при работе с коллекцией Николаевского городища Партизанского района, полученной в 1997 г. во время археологической разведки Ю.Г. Никитина. В том же году был собран материал на Смольнинском городище, найденный жителем пос. Анучино Василенко В.В., который передал коллекцию в сектор средневековой археологии Института истории, археологии и этнографии народов Дальнего Востока ДВО РАН (Гельман, 2006), после чего В.Э. Шавкуновым в течение нескольких лет проводились археологические раскоп- ки этого памятника (Шавкунов, 2004, 2009). Материал Смольнинского городища выпадал из привычных исследователям характеристик других средневековых комплексов региона, что позволило В.Э. Шавкунову сначала обосновать культурную специфику памятника, а затем выявить серию подобных объектов в центральной части и на юго-востоке Приморья (Шавкунов, 2015, с. 7). Начиная с 2009 и по 2013 г. В.Э. Шавкуновым проводились раскопки на городище Шайга-Редут, материалы которого продемонстрировали идентичность с находками на Смольнинском городище (Шавкунов, 2009, 2011, 2012, 2013). Результаты своих исследований николаевской (смольнинской) культуры Шавкунов В.Э. изложил в монографической работе «Памятники смольнинской культуры Приморья (по материалам раскопок городищ Смольнинское и Шайга-Редут) (Шавкунов, 2015).

Многие исследователи сталкивались с керамикой с «вафельной» выбивкой в ходе разведок и стационарных раскопок, не уточняя ее культурную принадлежность. Поэтому в фондах Музея Института истории, археологии и этнографии народов Дальнего Востока ДВО РАН имеются коллекции средневековых памятников, которые нуждаются в детальном пересмотре и анализе. Также научная база стихийно пополняется случайными находками и подъемным материалом, обнаруженным в результате сельскохозяйственных работ.

\section{Использованные источники}

В исследовании использовались как опубликованные, так и неопубликованные источники. Опубликованные коллекции керамики происходят из городищ Николаевское (Партизанского района), Смольнинское, Шайга-редут (Гельман, 2006; Шавкунов, 2015; Дъякова, Шавкунов, 2012; Жущиховская, Шавкунов, 2006; Жущиховская, 2009).

Николаевское городище находится в пос. Николаевское Партизанского района на левом берегу р. Водопадная. Площадь городища 30 га, периметр вала - 2280 м. Первая представительная коллекция керамики, позволившая выделить ее в особую группу и отнести к периоду между бохайской археологической культурой (VIII - 1-я треть X вв.) и культурой чжурчжэней эпохи Восточное Ся (1215-1233 гг.), была получена на территории многослойного памятника Николаевского городища Партизанского района в долине р. Партизанской (Сучан). Первые научные сведения о городище появлялись ещё в конце XIX века благодаря И. Лопатину, Палладию Кафарову, 
Г.Д. Маркову, Ф.Ф. Буссе и др. В 1955, 1959 гг. городище обследовал и собрал подъёмный материал Э.В. Шавкунов (Российский Дальний Восток..., 2005). После долгого перерыва, во время археологической разведки городище было обследовано Никитиным Ю.Г. в 1997 году, был заложен разведочный раскоп (Гельман, 2006). Опубликованные керамические материалы включают 116 фрагментов керамики. Археологические раскопки Николаевского городища были проведены Артемьевой Н.Г. в 2003 и 2004 году. Было заложено 6 раскопов

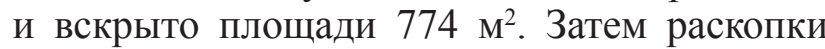
продолжались в 2007 году и с 2009 по 2011 гг. (Артемьева, 2004, 2005, 2007, 2009, 2010, 2011). Количество полученной за последние полевые сезоны керамики с «вафельной» выбивкой на этом памятнике пока остается неизвестным.

Смольнинское городище находится в Анучинском районе Приморского края в среднем течении р. Арсеньевки, в 2 км к юго-востоку от с. Смольное и в 17 км к югу от с. Анучино. Памятник к началу раскопок уже был частично разрушен рекой, площадь составила

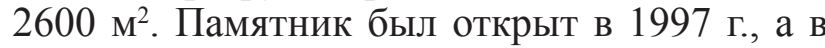
1999 г. здесь впервые были проведены раскопки Шавкуновым В.Э., которые продолжились в 2004, 2007 и 2008 гг. (Шавкунов, 2015). При раскопках Смольнинского городища в 2004 и 2008 гг. найдено 2386 фрагментов керамики, подавляющее большинство которых покрыто «вафельным» орнаментом.

В 1996 году В.И. Болдиным и Ю.Г. Никитиным было открыто городище Павловка-2, расположенное в долине на левом берегу p. Павловки, правого притока р. Уссури, в Чугуевском районе, в 4 км к востоку от с. Павловка. Площадь городища составляет 1444 м². $^{2}$. Памятник является однослойным. В результате шурфовки и сбора подъемного материала было найдено 44 фрагмента керамики, которую можно отнести к николаевской (смольнинской) культуре (Гельман, 2006; Шавкунов, 2015).

Чугуевское городище находится в долине на правой стороне р. Уссури, на территории районного центра с. Чугуевка. Впервые о нём сообщил в 1888 г. Ф.Ф. Буссе. В 1954-1955 гг. памятник обследовал А.П. Окладников. В 1956 г. Э.В. Шавкунов зафиксировал стратиграфию городища, которое оказалось двухслойным (Шавкунов, 2005). В 1996 г. был собран подъемный материал на Чугуевском городище. Было найдено 50 фрагментов средневековой керамики, среди которых лишь несколько фрагментов имели следы «вафельной» выбивки (Гельман, 2006).

Городище Стеклянуха-1 расположено в долине на правой стороне р. Шкотовки, в пределах с. Стеклянуха (Шкотовский район). Площадь памятника составляет 6 га, периметр 1000 м. Впервые о нём сообщил Л.А. Кропоткин. В 1956 г. городище было обследовано Э.В. Шавкуновым. В 1985-1987 гг. на памятнике вёл раскопки А.В. Александров, установивший, что городище является многослойным (Российский Дальний Восток..., 2005). В 2001 г. была собрана керамика с «вафельной» выбивкой в качестве подъемного материала на Стеклянухинском городище в количестве 21 фрагмента (Гельман, 2006).

В 2003 г. в Анучинском районе на поселении Анучино-27, расположенном на огородах на правом берегу р. Арсеньевки, В.В. Василенко был собран и передан в Институт истории подъемный материал в виде нескольких фрагментов с вафельной выбивкой (Гельман, 2006).

Начиная с 2009 и по 2013 г. Шавкуновым В.Э. проводились раскопки на городище Шайга-Редут. Городище расположено в Партизанском районе, в долине на левом берегу р. Партизанской, в 3,5 км к югу-западу от с. Южная Сергеевка. Впервые о памятнике сообщил в 1891 г. Иванов Д.Л. В 1963 году его обследовал и снял план Э.В. Шавкунов. В 2009, 2011-2013 гг. раскопки городища проводились В.Э. Шавкуновым, в результате

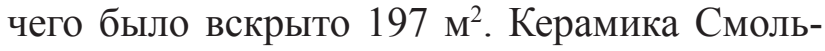
нинского городища и городища Шайга-Редут была тщательно исследована Жущиховской И.С. (Шавкунов, 2015). Материалы опубликованы частично, при работе с коллекцией и отчётами об археологических раскопках автор данной статьи выяснил, что за всё время стационарных раскопок в 2009, 2011-2013 гг. было найдено 4509 фрагментов керамики, относящейся к николаевской (смольнинской) культуре.

Археологические раскопки Николаевского городища были проведены Артемьевой Н.Г. в 2003 и 2004 году. Было заложено 6 раскопов и вскрыто 774 кв. м площади. Затем раскопки продолжались в 2007 году и с 2009 по 2011 гг. (Артемьева, 2004, 2005, 2007, 2009, 2010, 2011). Неопубликованные керамические материалы николаевской (смольнинской) культуры представлены в отчётах об археологических исследованиях Николаевского городища в Партизанском районе (Артемьева, 2004; 2005), Смольнинского городища (Шавкунов, 
2005, 2010), городища Шайга-Редут (Шавкунов, 2010, 2012-2014).

Неопубликованные керамические материалы николаевско-смольнинской культуры представлены коллекциями из поселения Малаза и местонахождения в долине реки Партизанской и притока, p. Сергеевки, переданные в 2018 г. из музея школы с. Сергеевка О.Н. Пузыревской в сектор раннесредневековой археологии ИИАЭ ДВО РАН. Многочисленные материалы из этих коллекций найдены в Партизанском районе как и в ходе раскопок (Пузыревская, 1995), так и в результате сборов после проведения пахотных работ долине реки. Эти коллекции включают керамику с признаками, характерными для николаевской (смольнинской) культуры, поэтому они рассматриваются вместе с остальными материалами уже известных памятников.

Памятник Малаза-1 находится на правом берегу реки Сергеевки в двух километрах к северу от с. Сергеевка. Площадь городища составляет около 15 га. Городище с трёх сторон опоясано рвом. Памятник открыт в 1995 году О.Н. Пузыревской и сильно пострадал от проводившихся в то время работ по строительству моста через p. Сергеевку. Около 30 фрагментов керамики николаевской (смольнинской) культуры было передано в ИИАЭ ДВО РАН (Пузыревская, 1995).

Местонахождение располагается на бывшем аэродромном поле напротив села Южная Сергеевка. В коллекции присутствует около 30 фрагментов сосудов, относящихся к николаевской (смольнинской) культуре.

Таким образом, география нашего исследования ограничивается Партизанским, Анучинским, Шкотовским и Чугуевским районами, содержащими наиболее явные проявления николаевской (смольнинской) культуры, и включает в себя долины реки Партизанской и её притоков - р. Сергеевки, Орлинки, Фроловки, Ратной, p. Арсеньевки, р. Уссури.

\section{Морфология керамики николаевской (смольнинской) культуры}

Керамика николаевской (смольнинской) культуры изготавливалась из глины с незначительным количеством грубых примесей, наиболее благоприятной для эффективного применения техники выбивки (Rye, 1981, p. 85). Сосуды собирались горизонтальноленточным налепом на гончарном круге. После оформления сосуда производилась выбивка, которая производилась до формирования венчика. Следы применения этого технологического приема могут покрывать изделие в верхней части до устья, ручки, стенки, донную и придонную части. Сосуды с выбивкой имеют преимущественно округлую форму тулова и зауженную горловину. Это объясняется тем, что сосуд легко захватывать и вращать, когда одна рука находится внутри (Rye, 1981, c. 85). Выбивка при изготовлении керамики в николаевской (смольнинской) культуре проводилась не только колотушкой с «вафельной» нарезкой, но и полосчатой, а также гладкой. Следы колотушки могут быть слегка заглажены тонким слоем глины или мокрой рукой (тряпкой) по всему сосуду, но чаще всего заглаживание производилось для дополнительного украшения изделия в некоторых его частях (в основном на горловине). После выбивки следовал обжиг, температура которого могла составлять $800-900^{\circ} \mathrm{C}$. Для рассмотренной керамики характерны темносерые, светло-серые, чёрные, и намного реже оранжевые, светло-коричневые тона.

Стоит отметить, что проанализированный материал в основном фрагментарен, так как был обнаружен на памятниках, подвергшихся сильным антропогенному и природному воздействиям. Единственный археологически целый сосуд обнаружен на городище ШайгаРедут, представительные примеры верхних и нижних частей сосудов (в отдельности) были найдены на местонахождении в с. Южная Сергеевка. Так как средневековая керамика VIII-XIII вв. содержит сходные формы, типы сосудов определимы даже в случае частичной сохранности по их размерам и морфологическим особенностям (Гельман, 2006; Гельман, 2018; Тупикина, 1996).

В керамике николаевской (смольнинской) культуры выделены такие типы сосудов, как горшки, корчаги, пароварки, миски и чаши, банки, вазы, крышки, которые определялись и систематизировались по верхним и донным частям сосудов.

К горшкам были отнесены части сосудов среднего размера с венчиками диаметром от 11 до 20 см с различной толщиной стенок. Горшки были обнаружены на всех памятниках, отнесённых в николаевской (смольнинской) культуре, и представляют собой верхние части сосудов закрытого типа, горловина которых хорошо профилирована и может быть как высотой 2 см, так и 5-6,5 см (рис. 5: 1, 2). На городище Шайга-Редут был обнаружен единственный археологически целый сосуд николаевской (смольнинской) культуры (рис. 1: 1). Изделие имеет горшковидную форму, венчик раздвоен горизонтальной бороздкой, 

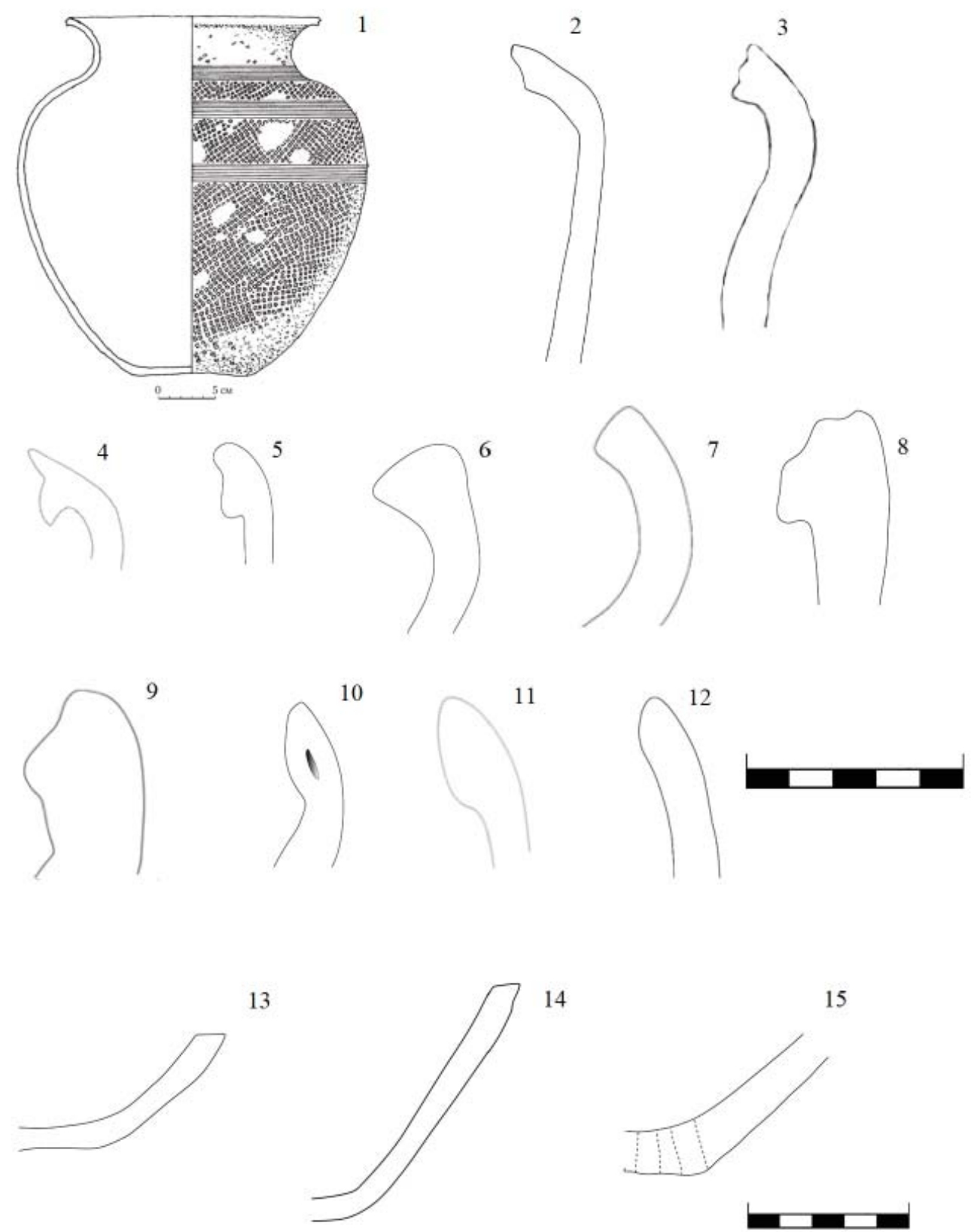

14

Рис. 1. Морфологические детали керамики николаевской (смольнинской) культуры. 1 - сосуд-горшок, найденный на городище Шайга-Редут (Шавкунов, 2015); 2-12 - венчики; 13-14 - закруглённые донья; 15 - дно пароварки. Изображения подготовлены Гельман Е.И., Шавкуновым В.Э, Боруруевой А.А.

Fig. 1. Morphological details of ceramics of Nikolaevskaya (Smolninskaya) culture. 1 - pot discovered at Shayga-Redut hillfort (Shavkunov, 2015); 2-12 - rims; 13-14 - rounded bottoms; 15 - steamer bottom.

The images were prepared by E.I. Gel'man, V.E. Shavkunov, A.A. Borurueva

дно закруглено. Сосуд хорошо профилирован и имеет в целом округлую форму и чёткую горловину. Венчики горшков отогнуты наружу и чаще всего раздвоены горизонтальной бороздкой, имеют заострённое устье и слегка оттянутый вниз «Хвостик» (рис. 1: 4), также могут иметь кососрезанный край (рис. 1: 6). На городищах Смольнинской и Шайга-Редут обнаружены венчики, разделенные двумя горизонтальными бороздками с заострённым устьем (рис. 1: 3). Донья сосудов закруглены посредством выбивки на месте стыка с туловом. На местонахождении напротив с. Южная Сергеевка, недалеко от поселения Малаза-I, обнаружены хорошо сохранившиеся верхние и нижние части сосудов (рис. 3: 1-4), форма и исполнение которых идентичны с археологически целым сосудом, найденным на городище Шайга-Редут. Горшки в первую очередь являются кухонной посудой, при этом могли использоваться не только для приготовления пищи. 
Корчаги представлены фрагментами крупных сосудов с венчиками от 32 до 50,1 см в диаметре (рис. 4). Они являются одними из самых распространённых форм в керамике николаевской (смольнинской) культуры. Корчаги были обнаружены на всех памятниках культуры и отличаются от горшков очень крупными размерами и статистически большим количеством в коллекциях венчиков с косо срезанным краем значительного диаметра (рис. 1: 7). Также встречаются закруглённые (рис. 1: 11), трубчатые (рис. 1: 10) и трёхгубые венчики (рис. 1: 8). Донья являются закруглёнными, но встречаются и плоскодонные экземпляры. Корчаги, судя по аналогичным сосудам в бохайской и чжурчжэньской керамике, предназначались для хранения как сухих и сыпучих продуктов, так и для хранения жидкостей (Гельман, 2018; Тупикина, 1996).

Корчажкам принадлежат частично сохранившиеся сосуды с диаметром венчиков от 20 до 30 с небольшим сантиметров. К корчажкам относятся пароварки с диаметром дна 10-16,5 см (рис. 5: 6, 7). Венчики пароварок обычно имеют кососрезанный край, а донья могут быть плоскими и с закругленными краями (рис. 1: 15). Диаметр отверстий варьирует от 0,4 до 0,7 см. Многочисленные пеньковые ручки в первую очередь использовались для корчажек с функцией пароварок.

Чаши и миски включают в себя сосуды открытого типа со средней толщиной стенок и диаметром венчика от 12 до 15,5 см. Миски и чаши имеют открытую форму, стенки расширяются от дна к венчику (рис. 5: 5). Венчики у них слегка отогнуты наружу и делятся на несколько типов: с косо срезанным краем, прямые с закруглённым устьем (рис. 1: 12), на городище Малаза-I встречаются отогнутые на 90 градусов венчики. Миски и чаши также обнаружены на Николаевском, Смольнинском, Шайга-редут, Стеклянуха-1 городищах. Чаши и миски относятся к столовой посуде.

К банкам отнесены тонкостенные сосуды с венчиками диаметром от 20 до 25 см (рис. $5: 3,4)$. Вазы отличаются вытянутым туловом и сильно выделенной горловиной с венчиком 10 см в диаметре. Сосуды баночной формы

Рис. 2. Типы ручек в николаевской (смольнинской) культуре. Графические изображения выполнены Гельман Е.И.

Fig. 2. Types of handles in the Nikolaevskaya (Smolninskaya) culture. Graphic images by E.I. Gel'man встречаются в коллекциях Николаевского (Партизанского района), Смольнинского, Чугуевского и на местонахождении напротив с. Южная Сергеевка. Они слабопрофилированные, имеют цилиндрическую форму тулова с почти прямыми стенками (рис. 3: 3). Венчики данного типа сосудов обычно отогнуты наружу и разделены одной или двумя бороздками, имеют заострённое устье и оттянутый нижний край (рис. 1: 2, 5).

Некоторые части сосудов, имеющие сильно профилированную горловину и вытянутое тулово, могут быть предварительно отнесены к вазам. Вазовидные сосуды обнаружены на городищах Смольнинское, Шайга-Редут и местонахождении у с. Южная Сергеевка. Венчики отогнуты наружу и имеют две формы: с косо срезанным краем и венчики с одной или двумя горизонтальными бороздками.

Ручки встречаются на всех памятниках николаевской (смольнинской) культуры и могут относиться как корчажкам, включая пароварки, так и корчагам. Форма их настолько специфична, что в сочетании со следами выбивки ручки являются ярким культурным маркером. Они называются пеньковыми, имеют глиняный штырь на одном конце и вставляются в подготовленные в стенках сосудов отверстия и дополнительно примазываются. Ручки разделяются на несколько типов:

- прямоугольные в плане и сечении с немного заглаженными следами выбивки (рис. 2: 3), с не заглаженными оттисками (рис.
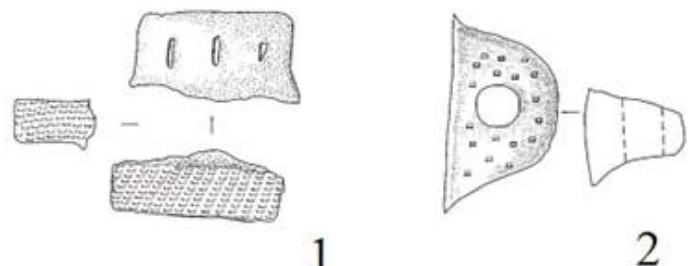

1
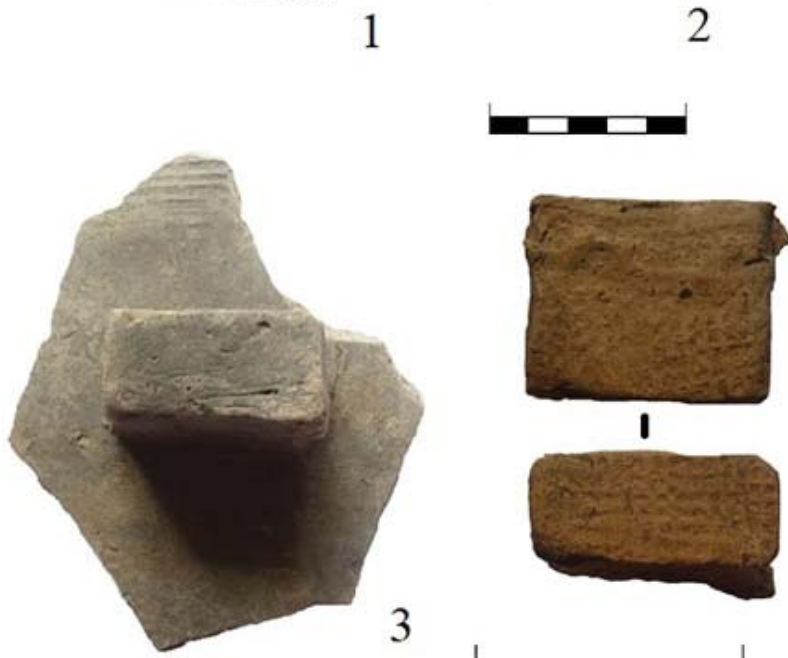

I

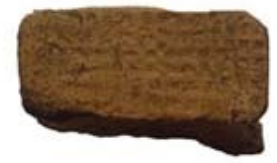

3 

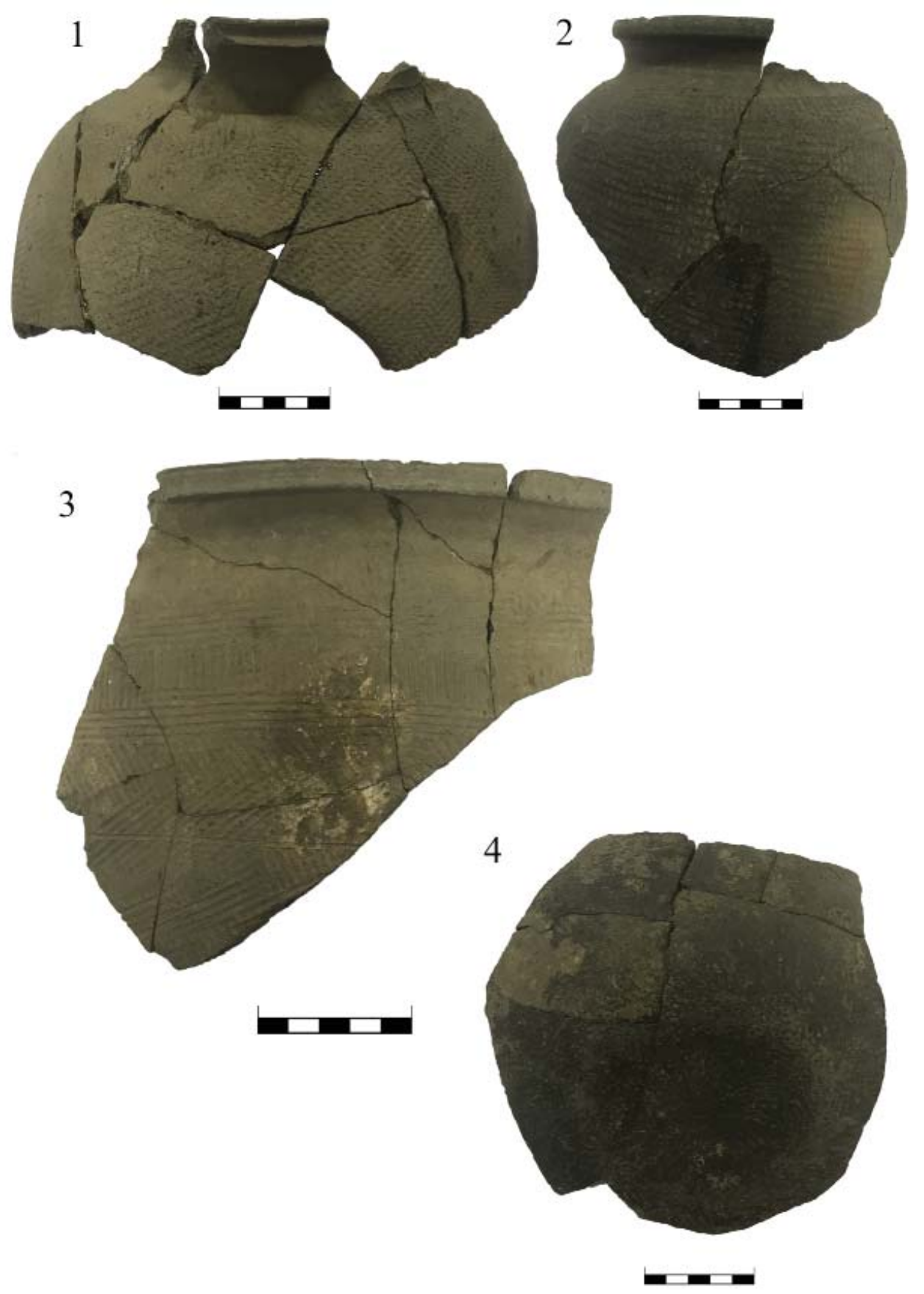

Рис. 3. Фрагменты сосудов николаевской (смольнинской) культуры.

1, 2 - горшковидные сосуды; 2 - баночный сосуд; 4 - донье

Fig. 3. Fragments of vessels of Nikolaevskaya (Smolninskaya) culture.

1, 2 - pot-shaped vessels; 2 - jar vessel; 4 - bottom

2: 4), с трёмя вдавлениями на видимой снаружи поверхности (рис. 2: 1), с косо срезанными внешними краями;

- петельчатые, округлой формы и с закруглёнными краями (рис. 2: 2), имеют сквозное отверстие в середине.

Различные виды прямоугольных ручек найдены на Николаевском (Партизанского района), Смольнинском, Шайга-Редут, закруглённые - на городищах Николаевское и Смольнинское, ручка с кососрезанными внешними краями обнаружена на Смольнинском городище.

\section{Bblвodbl}

Рассмотренные формы сосудов изготовлены с применением техники выбивки колотушкой и имеют схожие технологические и морфологические характеристики. Систематизация и классификация керамики николаевской (смольнинской) культуры, несмотря на фрагментарность, позволили выделить такие формы сосудов, как горшки, корчаги, корчажки (в том числе пароварки), миски и 

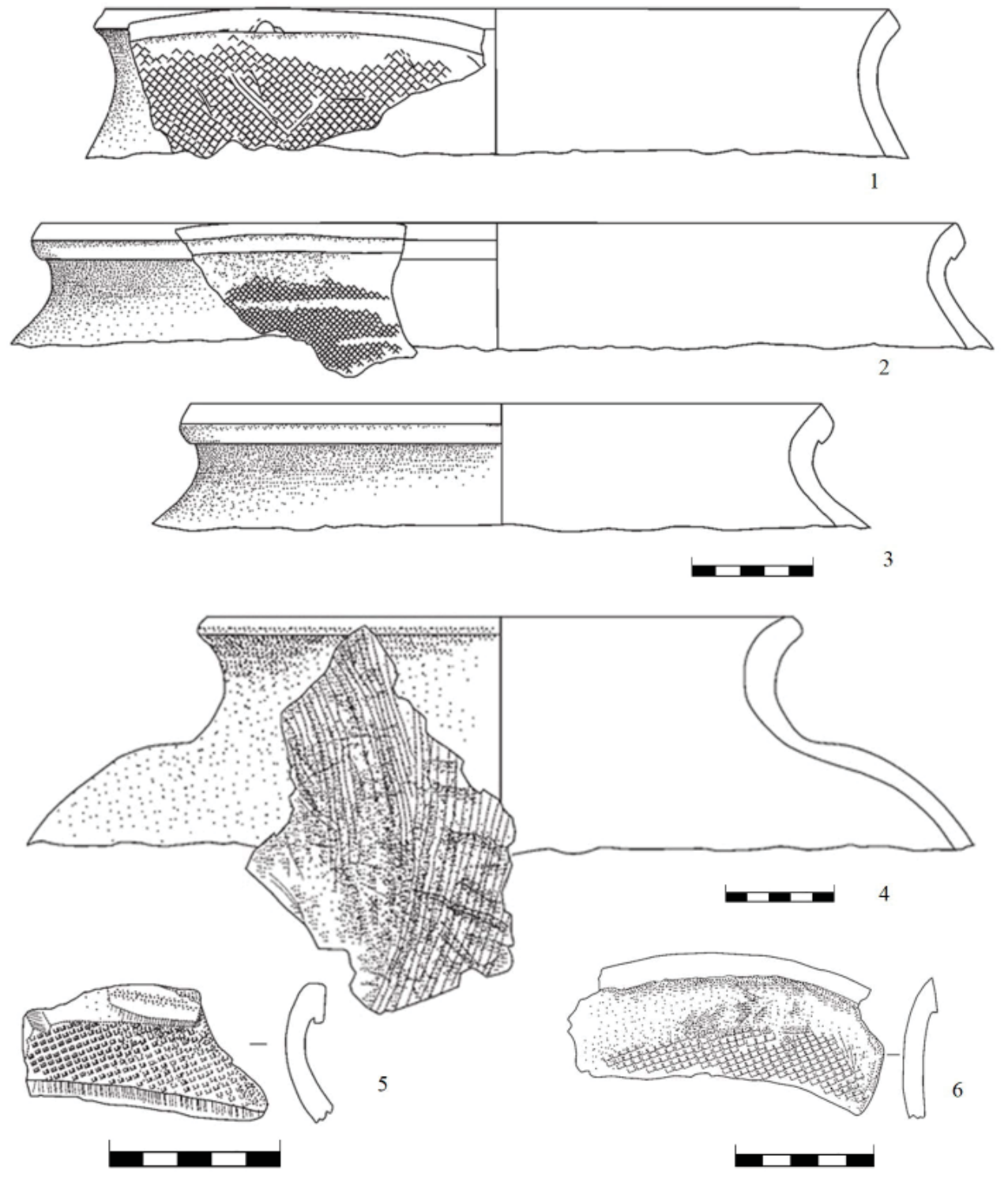

Рис. 4. Классификация форм сосудов по ранее опубликованным источникам (по Гельман, 2006), верхние части корчаг

Fig. 4. Classification of the forms of vessels according to previously published sources (after: Gel'man, 2006), upper parts of pots.

чаши, банки, вазы. Горшки и корчаги являются самыми распространёнными формами и встречаются на всех памятниках николаевской (смольнинской) культуры, соответственно, морфологические детали данных типов сосудов наиболее широко представлены коллекциях. Небольшая разница в наборе форм на различных археологических памятниках объясняется недостаточной степенью изученности многих памятников.

Анализ морфологических деталей керамики показал, что венчики фигурных форм (с одной или двумя бороздками, с оттянутыми и заострёнными устьем или нижним краем) соответствуют сосудам с тонкими стенками и могли принадлежать горшкам и банкам, трёхгубые - только толстостенным крупным сосудам типа корчаг, венчики с косо срезанным краем и закруглённые встречаются у сосудов с различной толщиной стенок: у горшков, корчаг и корчажек, чаш и мисок.

Ручки могут быть пеньковыми прямоугольной формы или петельчатыми. Встречаются прямоугольные ручки с кососрезанны- 

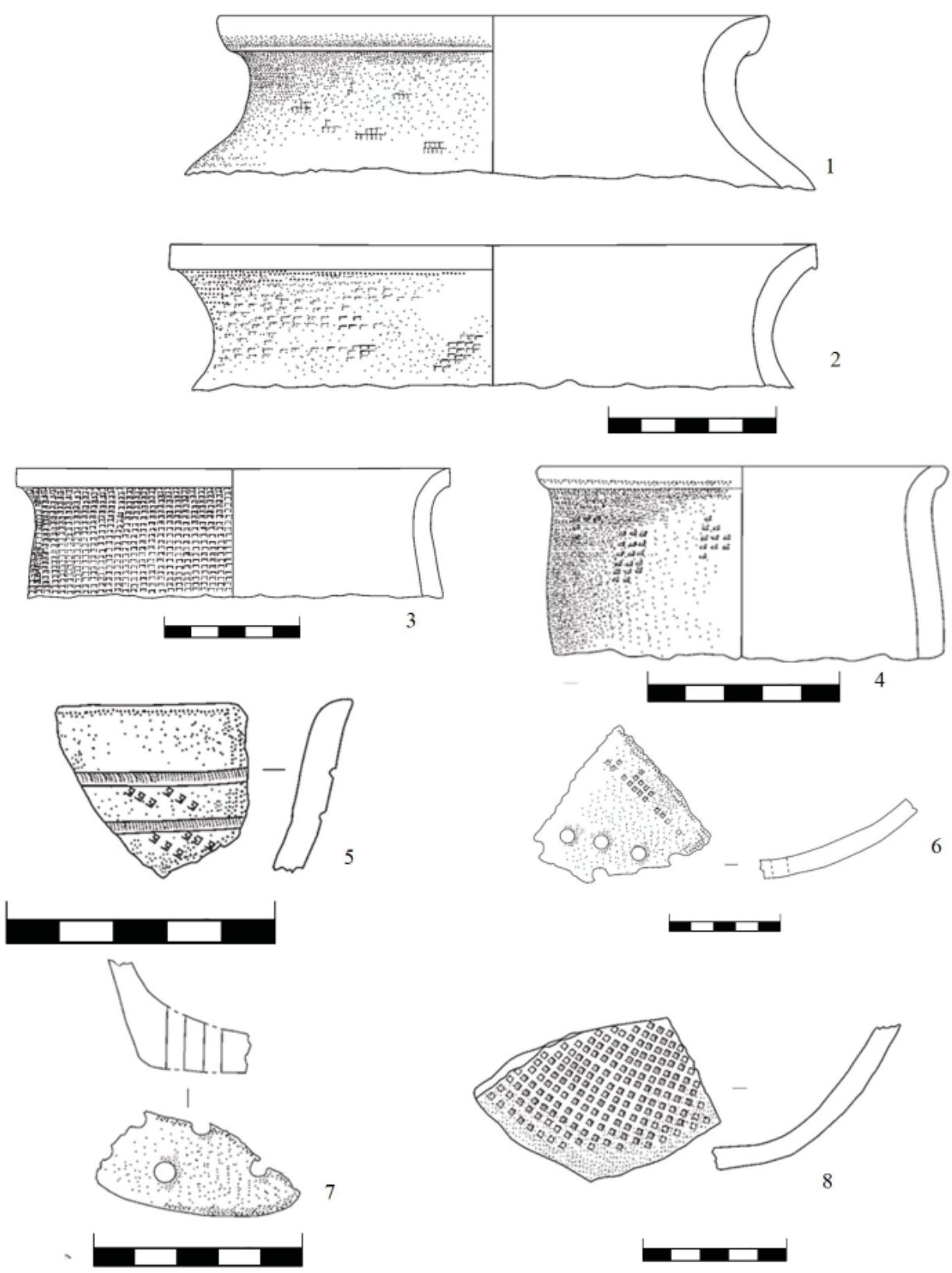

Рис. 5. Классификация форм сосудов по ранее опубликованным источникам (по Гельман, 2006). 1, 2 - верхние части горшков; 3, 4 - верхние части банок; 5 - венчик чаши; 6, 7 - донья пароварок; 8 закруглённое дно.

Fig. 5. Classification of vessel shapes on the basis of previously published sources (after: Gel'man, 2006). 1, 2 - pot tops; 3, 4 - jar tops; 5 - bowl rim; 6, 7 - steamer bottom; 8 - rounded bottom.

ми наружными краями. Донья николаевской (смольнинской) культуры нередко закруглены на месте стыка дна и придонной части. Часть доньев являются плоскими.

В результате исследования можно сказать, что в николаевской (смольнинской) культуре производились унифицированные формы сосудов. Они по степени разнообразия значительно уступают набору форм бохайской керамики. Но, с другой стороны, такое небольшое количество основных типов сосудов сближает рассмотренную керамику с посудой из памятников чжурчжэней XII-XIII вв. и других сопредельных с Приморьем территорий.

Наличие выбивки в виде технического орнамента на поверхности керамики является лишь одним из культурных признаков, при этом следы технического приёма частично заглаживались, в результате чего при интерпретации керамического материала из памятников николаевской (смольнинской) культуры необходимо учитывать форму сосудов, морфологические детали и орнамент. 
Приносим нашу искреннюю благодарность Е.И. Гельман за предоставленные материаль и консультации, заведующей музеем школь с. Сергеевка О.Н. Пузыревской за возможность работы с коллекциями, которые были пере- даны в Сектор раннесредневековой археологии, а также В.Э. Шавкунову и Лаборатории археологии Приамурья за возможность работы с коллекииями Смольнинского городища и городищза Шайга-Редут.

\section{ЛИТЕРАТУРА}

Артемьева Н.Г. Отчет об археологических исследованиях Николаевского городища в Партизанском районе Приморского края в 2003 году. Владивосток, 2004. / Архив ИИАЭ ДВО РАН.

Артемьева Н.Г. Отчет об археологических исследованиях Николаевского городища в Партизанском районе Приморского края в 2004 году. Владивосток, 2005. / Архив ИИАЭ ДВО РАН.

Артемьева Н.Г. Отчет об археологических исследованиях Николаевского городища в Партизанском районе Приморского края в 2005 году. Владивосток, 2006./ Архив ИИАЭ ДВО РАН.

Артемьева Н.Г. Отчет об археологических исследованиях Николаевского городища в Партизанском районе Приморского края в 2007 году. Владивосток, 2008./ Архив ИИАЭ ДВО РАН.

Артемьева Н.Г. Отчет об археологических исследованиях Николаевского городища в Партизанском районе Приморского края в 2009 году. Владивосток, 2010. / Архив ИИАЭ ДВО РАН.

Артемьева Н.Г. Отчет об археологических исследованиях Николаевского городища в Партизанском районе Приморского края в 2010 году. Владивосток, 2011. / Архив ИИАЭ ДВО РАН.

Артемьева Н.Г. Отчет об археологических исследованиях Николаевского городища в Партизанском районе Приморского края в 2011 году. Владивосток, 2012. / Архив ИИАЭ ДВО РАН.

Гельман Е.И. Керамика чжурчжэней Приморья // Россия и АТР. 2006. №1. С. 93-104.

Гельман Е.И. Керамика Краскинского городища // Мультидисциплинарные исследования в археологии. 2018. №2. С. 40-64.

Жущиховская И.С., Шавкунов В.Э. Новая культурная традиция в средневековом гончарстве Приморья // Вестник ДВО РАН. 2006. №2. С. 97-108.

Пузыревская О.Н. Археологическая разведка на реке Партизанской и её притоках в районе с. Сергеевки. 1995./ Личный архив О. Н. Пузыревской.

Российский Дальний Восток в древности и средневековье: открытия, проблемы, гипотезы / Отв. ред. Ж.В. Андреева. Владивосток: Дальнаука. 2005. 559 с.

Тупикина С.M. Керамика чжурчжэней Приморья XII-начала XIII в. (по материалам археологических исследований Шайгинского городища). Владивосток: Дальнаука. 1996. 120 с.

Шавкунов Э.В. Отчет о результатах полевых исследований на территории Приморского края, проводившихся в 1955-1956 гг. / Архив ИА РАН, 1956.

Шавкунов Э.В. Отчет об археологических исследованиях в долине р. Сучан в 1962 г. / Архив ИА PAH, 1962.

Шавкунов Э.В. Отчет об археологических исследованиях на юге Приморского края в 1963 г. / Архив ИА РАН, 1963.

Шавкунов В.Э. Отчет об археологических работах на Смольнинском городище в Приморском крае в 2008 г. / Архив ИИАЭ ДВО РАН, 2009.

Шавкунов В.Э. Отчет об археологических работах на Смольнинском городище в Анучинском районе Приморского края в 2004 г. 2005./ Архив ИИАЭ ДВО РАН.

Шавкунов В.Э. К вопросу о восточной границе государства бохай // Россия и АТР. 2005. №.4. С. $27-32$.

Шавкунов B.Э. Отчет об археологических работах на городище Шайга-Редут в Партизанском районе Приморского края в 2009 году. Владивосток, 2010. / Архив ИИАЭ ДВО РАН,

Шавкунов B.Э. Отчет об археологических работах на городище Шайга-Редут в Партизанском районе Приморского края в 2011 году. Владивосток, 2012. / Архив ИИАЭ ДВО РАН.

Шавкунов B.Э. Отчет об археологических работах на городище Шайга-Редут в Партизанском районе Приморского края в 2012 году. Владивосток, 2013. / Архив ИИАЭ ДВО РАН.

Шавкунов B.Э. Отчет об археологических работах на городище Шайга-Редут в Партизанском районе Приморского края в 2013 году. Владивосток, 2014. / Архив ИИАЭ ДВО РАН.

Шавкунов В.Э. Памятники смольнинской культуры Приморья (по материалам раскопок городищ Смольнинское и Шайга-Редут) / АТР: археология, этнография, история. Вып. 4. Владивосток: ИИАЭ ДВО РАН, 2015. 164 с. 
Rye O.S. Pottery Technology. Washington: Taraxacum Inc. 1981. 198 p.

\section{Информация об авторе:}

Боруруева Анна Александровна, старший лаборант, Институт истории, археологии и этнографии народов Дальнего Востока ДВО РАН (г. Владивосток, Россия); master.anna888@gmail.com

\section{REFERENCES}

Artem'eva, N. G. 2004. Otchet ob arkheologicheskikh issledovaniiakh Nikolaevskogo gorodishcha v Partizanskom raione Primorskogo kraia v 2003 godu (Report on Archaeological Studies of Nikolaevka Hillfort in the Partizansky District of Primorsky Krai in 2003). Vladivostok. Archive of the Institute of History, Archaeology and Ethnography of the Peoples of the Far-East, Far- Eastern Branch of the RAS (in Russian).

Artem'eva, N. G. 2005. Otchet ob arkheologicheskikh issledovaniiakh Nikolaevskogo gorodishcha v Partizanskom raione Primorskogo kraia v 2004 godu (Report on Archaeological Studies of Nikolaevka Hillfort in the Partizansky District of Primorsky Krai in 2004). Vladivostok. Archive of the Institute of History, Archaeology and Ethnography of the Peoples of the Far-East, Far-Eastern Branch of the RAS (in Russian).

Artem'eva, N. G. 2006. Otchet ob arkheologicheskikh issledovaniiakh Nikolaevskogo gorodishcha v Partizanskom raione Primorskogo kraia v 2005 godu (Report on Archaeological Studies of Nikolaevka Hillfort in the Partizansky District of Primorsky Krai in 2005). Vladivostok. Archive of the Institute of History, Archaeology and Ethnography of the Peoples of the Far-East, Far-Eastern Branch of the RAS (in Russian).

Artem'eva, N. G. 2008. Otchet ob arkheologicheskikh issledovaniiakh Nikolaevskogo gorodishcha $v$ Partizanskom raione Primorskogo kraia v 2007 godu (Report on Archaeological Studies of Nikolaevka Hillfort in the Partizansky District of Primorsky Krai in 2007). Vladivostok. Archive of the Institute of History, Archaeology and Ethnography of the Peoples of the Far-East, Far-Eastern Branch of the RAS (in Russian).

Artem'eva, N. G. 2010. Otchet ob arkheologicheskikh issledovaniiakh Nikolaevskogo gorodishcha v Partizanskom raione Primorskogo kraia v 2009 godu (Report on Archaeological Studies of Nikolaevka Hillfort in the Partizansky District of Primorsky Krai in 2009). Vladivostok. Archive of the Institute of History, Archaeology and Ethnography of the Peoples of the Far-East, Far-Eastern Branch of the RAS (in Russian).

Artem'eva, N. G. 2011. Otchet ob arkheologicheskikh issledovaniiakh Nikolaevskogo gorodishcha v Partizanskom raione Primorskogo kraia v 2010 godu (Report on Archaeological Studies of Nikolaevka Hillfort in the Partizansky District of Primorsky Krai in 2010). Vladivostok. Archive of the Institute of History, Archaeology and Ethnography of the Peoples of the Far-East, Far-Eastern Branch of the RAS (in Russian).

Artem'eva, N. G. 2012. Otchet ob arkheologicheskikh issledovaniiakh Nikolaevskogo gorodishcha v Partizanskom raione Primorskogo kraia v 2011 godu (Report on Archaeological Studies of Nikolaevka Hillfort in the Partizansky District of Primorsky Krai in 2011). Vladivostok. Archive of the Institute of History, Archaeology and Ethnography of the Peoples of the Far-East, Far-Eastern Branch of the RAS (in Russian).

Gel'man, E. I. 2006. In Rossiya i ATR (Russia and Asia-Pacific Region) (1), 93-104 (in Russian).

Gel'man, E. I. 2018. In Mul'tidistsiplinarnye issledovaniia $v$ arkheologii (Multidisciplinary Studies in Archaeology) (2), 40-64 (in Russian).

Zhushchikhovskaya, I. S., Shavkunov, V. E. 2006. In Vestnik Dal'nevostochnogo Otdeleniya RAN (Vestnik of Far Eastern Branch of Russian Academy of Sciences) 2, 97-108 (in Russian).

Puzyrevskaya, O. N. 1995. Arkheologicheskaia razvedka na reke Partizanskoi i ee pritokakh v raione s. Sergeevki (Archaeological Exploration on the Partizanskaya River and its Tributaries in the Area of Sergeevka Village). Personal archives of O.N. Puzyrevskaya (in Russian).

Andreeva, Zh. V. 2005. (ed.). Rossiiskii Dal'nii Vostok v drevnosti i srednevekov'e: otkrytiia, problemy, gipotezy (The Russian Far East in Antiquity and the Middle Ages: Discoveries, Issues, Hypotheses). Vladivostok: "Dal'nauka" Publ. (in Russian).

Tupikina, S. M. 1996. Keramika chzhurchzhienei Primor'ia XII-nachala XIII v. (po materialam arkheologicheskikh issledovanii Shaiginskogo gorodishcha) (Ceramics of the Jurchens from Primorye of the 12th-Early 13th Centuries (Based on Archaeological Study Materials of Shaiginskoe Hillfort)). Vladivostok: "Dal'nauka" Publ. (in Russian).

Shavkunov, V. E. 1956. Otchet o rezul'tatakh polevykh issledovanii na territorii Primorskogo kraia, provodivshikhsia v 1955-1956 gg. (Report on the Results of Field Studies in Primorsky Krai in 1955-1956). Archive of the Institute of Archaeology of the Russian Academy of Sciences (in Russian).

Shavkunov, V. E. 1962. Otchet ob arkheologicheskikh issledovaniiakh v doline r. Suchan v 1962 g. (Report on Archaeological Studies in the Valley of the Suchan River in 1962). Archive of the Institute of Archaeology of the Russian Academy of Sciences (in Russian). 
Shavkunov, V. E. 1963. Otchet ob arkheologicheskikh issledovaniiakh na iuge Primorskogo kraia v 1963 g.). (Report on Archaeological Studies in the South of Primorsky Krai in 1963). Archive of the Institute of Archaeology of the Russian Academy of Sciences (in Russian).

Shavkunov, V. E. 2005. Otchet ob arkheologicheskikh rabotakh na Smol'ninskom gorodishche $v$ Anuchinskom raione Primorskogo kraia v 2004 g. (Report on Archaeological Activities at Smolninsky Hillfort in the Anuchinsky District of the Primorsky Krai in 2004.). Archive of the Institute of History, Archaeology and Ethnography of the Peoples of the Far-East, Far-Eastern Branch of the RAS (in Russian).

Shavkunov, V. E. 2005. In Rossiya i ATR (Russia and Asia-Pacific Region) (4), 27-32 (in Russian).

Shavkunov, V. E. 2009. Otchet ob arkheologicheskikh rabotakh na Smol'ninskom gorodishchev Primorskom krae v 2008 g. (Report on Archaeological Activities at Smolninsky Hillfort in Primorsky Krai in 2008). Archive of the Institute of History, Archaeology and Ethnography of the Peoples of the Far-East, Far-Eastern Branch of the RAS (in Russian).

Shavkunov, V. E. 2010. Otchet ob arkheologicheskikh rabotakh na gorodishche Shaiga-Redut $v$ Partizanskom raione Primorskogo kraja v 2009 godu (Report on Archaeological Activities at Shayga-Redut Hillfort in the Partizansky District of Primorsky Krai in 2009). Archive of the Institute of History, Archaeology and Ethnography of the Peoples of the Far-East, Far-Eastern Branch of the RAS (in Russian).

Shavkunov, V. E. 2012. Otchet ob arkheologicheskikh rabotakh na gorodishche Shaiga-Redut $v$ Partizanskom raione Primorskogo kraja v 2011 godu (Report on Archaeological Activities at Shayga-Redut Hillfort in the Partizansky District of Primorsky Krai in 2011). Archive of the Institute of History, Archaeology and Ethnography of the Peoples of the Far-East, Far-Eastern Branch of the RAS (in Russian).

Shavkunov, V. E. 2013. Otchet ob arkheologicheskikh rabotakh na gorodishche Shaiga-Redut $v$ Partizanskom raione Primorskogo kraja v 2012 godu (Report on Archaeological Activities at Shayga-Redut Hillfort in the Partizansky District of Primorsky Krai in 2012). Archive of the Institute of History, Archaeology and Ethnography of the Peoples of the Far-East, Far-Eastern Branch of the RAS (in Russian).

Shavkunov, V. E. 2014. Otchet ob arkheologicheskikh rabotakh na gorodishche Shaiga-Redut $v$ Partizanskom raione Primorskogo kraja v 2013 godu (Report on Archaeological Activities at Shayga-Redut Hillfort in the Partizansky District of Primorsky Krai in 2013). Archive of the Institute of History, Archaeology and Ethnography of the Peoples of the Far-East, Far- Eastern Branch of the RAS (in Russian).

Shavkunov, V. E. 2015. Pamiatniki smol'ninskoi kul'tury Primor'ia (po materialam raskopok gorodishch Smol'ninskoe i Shajga-Redut) (Monuments of the Smolninsky Culture of Primorye (Based on Materials from the Excavations of Smolninskoe and Shayga-Redut Hillforts)). Series: ATR: arkheologiia, etnografia, istoriia (Asia-Pasific Region: Archaeology, Ethnography, History) 4. Vladivostok: Institute of History, Archaeology and Ethnography of the Peoples of the Far-East, Far-Eastern Branch of the RAS (in Russian).

Rye, O. S. 1981. Pottery Technology. Washington: Taraxacum Inc. (in English).

\section{About the Author:}

Borurueva Anna A. Institute of History, Archaeology and Ethnography of the Peoples of the Far East of the Far Eastern Branch of the Russian Academy of Sciences. Pushkinskaya St., 89, Vladivostok, 690001, Russian Federation; master.anna888@gmail.com 